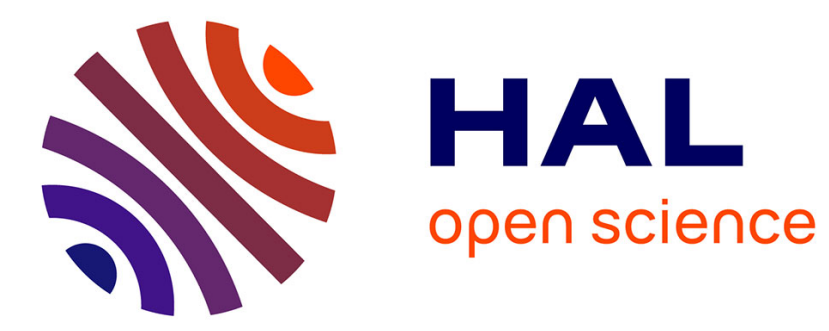

\title{
Serum C-reactive protein (CRP) and procalcitonin (PCT) levels and kinetics in patients with leptospirosis
}

\author{
J. Crouzet, J.-F. Faucher, M. Toubin, B. Hoen, J.-M. Estavoyer
}

\section{To cite this version:}

J. Crouzet, J.-F. Faucher, M. Toubin, B. Hoen, J.-M. Estavoyer. Serum C-reactive protein (CRP) and procalcitonin (PCT) levels and kinetics in patients with leptospirosis. European Journal of Clinical Microbiology and Infectious Diseases, 2010, 30 (2), pp.299-302. 10.1007/s10096-010-1088-7 . hal00640519

\section{HAL Id: hal-00640519 \\ https://hal.science/hal-00640519}

Submitted on 13 Nov 2011

HAL is a multi-disciplinary open access archive for the deposit and dissemination of scientific research documents, whether they are published or not. The documents may come from teaching and research institutions in France or abroad, or from public or private research centers.
L'archive ouverte pluridisciplinaire HAL, est destinée au dépôt et à la diffusion de documents scientifiques de niveau recherche, publiés ou non, émanant des établissements d'enseignement et de recherche français ou étrangers, des laboratoires publics ou privés. 
Serum C-reactive protein (CRP) and Procalcitonin (PCT) levels and kinetics in patients with leptospirosis

Julien Crouzet ${ }^{1}$, Jean-François Faucher ${ }^{1}$, Madeleine Toubin ${ }^{2}$, Bruno Hoen ${ }^{1}$, Jean-Marie Estavoyer $^{1}$

${ }^{1}$ Departement of Infectious Diseases, Besançon University Medical Center, 25030 Besançon cedex, France

${ }^{2}$ Besançon University Medical Center biochemistry laboratory, 25030 Besançon cedex, France

Corresponding author: Jean-François Faucher, Service des Maladies Infectieuses et Tropicales, Hôpital SaintJacques, 2, place Saint-Jacques, 25030 Besançon cedex, France

Email : jffaucher@chu-besancon.fr 


\section{INTRODUCTION}

Leptospirosis is a zoonotic disease of worldwide distribution caused by spirochetes of the genus Leptospira. Leptospirosis clinical presentation ranges from subclinical infections to severe multiorgan-dysfunction syndromes. There are similarities between clinical and pathophysiological features encountered in leptospirosis and those of severe sepsis due to gram negative bacteria. However, the low endotoxic potency of leptospiral lipopolysaccharides could explain that severe manifestations of leptospirosis occur later after the onset of disease, compared to severe manifestations of gram negative basteria sepsis [1].

In previous studies, we found elevated plasma triglycerides and TNF $\alpha$ levels [2] which may translate a systemic inflammatory response syndrome (SIRS), in patients with leptospirosis. The C-reactive protein (CRP) and procalcitonin (PCT) levels are elevated in SIRS and these biomarkers are available in routine practice. The aim of this retrospective study is to report on the levels and kinetics of the CRP and PCT in patients with non severe and severe leptospirosis.

\section{PATIENTS AND METHODS}

All patients with confirmed leptospirosis who were hospitalized between January 1999 and December 2006 in the infectious diseases department (Besançon University Hospital) were included.

The diagnostic criteria for leptospirosis, valid for non endemic areas, was a microscopic agglutination test (MAT) at a titer $\geq 100$ [3].

At admission, the following items were collected: age, gender, comorbidities, exposure to leptospirosis, body temperature, presence or absence of altered consciousness, haemorrhages, jaundice, oliguria, collapses, dyspnea. The following blood parameters were assessed: haemoglobin, haematocrit, leucocytes, platelets, prothrombin time, urea, creatinine, electrolytes, total bilirubin, ALAT and ASAT.

Severe leptospirosis was defined by the presence of at least one of the following [4,5]: altered mental status, seizures, pneumonia, use of mechanical ventilation, systolic blood pressure < $90 \mathrm{mmHg}$, arrhythmia and/or repolarisation disorders, use of vasopressive amines, oliguria ( $<500 \mathrm{~mL} /$ day), serum creatinine $>200 \mu \mathrm{mol} / \mathrm{L}$, platelets $<100,000 / \mu \mathrm{L}$.

Apache II and SOFA scores were also used in order to assess severity, but they were not taken into account for the definition of severe cases [5].

Samples were collected within $24 \mathrm{~h}$ after admission, and thereafter according to the length of hospitalisation. They were stored at $-20^{\circ} \mathrm{C}$ in order to further assess CRP and PCT levels. All samples were analysed in 2007.

CRP levels were measured by use of an immunoturbidimetry method (RXL analyzer, DadeBehring-Siemens). The lower limit of detection of the assay was $2 \mathrm{mg} / \mathrm{L}$. PCT levels were measured by use of an time-resolved amplified cryptate emission (TRACE) technology (Kriptor analyzer, BRAHMS ). The lower limit of detection of the assay was $0.06 \mathrm{ng} / \mathrm{mL}$.

The study was approved by the Institutional Review Board (Comite d'Ethique) of the Besançon University Hospital.

Discrete variables were expressed as counts (percentage) and continuous variables as median and range. Two independent groups of patients (the non severe leptospirosis group and the severe leptospirosis group) were compared with regard to demographic data, outcome, mean PCT levels, and CRP levels by the $\mathrm{X}^{2}$ test, the Fisher's exact test or the Mann-Whitney-U test, as appropriate. All statistical analyses were performed with SAS software, version 8.02 (SAS Institute Inc., Cary, NC). A two-tailed $p$ value of less than 0.05 was considered statistically significant. 


\section{RESULTS}

Thirty-six consecutive cases of confirmed leptospirosis, with a median age of 40 (range: 1071) were included (Table 1). Severe forms were found in 22 patients, and non severe forms in 14. Mean age $(p=0.05)$, serum creatinine $(p=0.05)$, severity scores $(p=0.001)$ were higher in patients with severe leptopsirosis, while mean platelets count $(\mathrm{p}=0.02)$ was higher in non severe patients. Time between first symptoms and admission, as well as length of hospitalization did not significantly differ between groups.

Leptospirosis was related to leisure activities in 26 patients and to professional exposure in 10 patients. Main serogroups were L. icterohaemmorhagiae in 12 patients et L. grippotyphosa in 10 patients.

A few patients $(n=4)$ had comorbidities: diabetes $(n=3)$ and chronic alcoholism $(n=1)$.

Among non severe forms, 3 had jaundice. Clinical findings in severe forms were the following: renal failure $(n=11)$, jaundice $(n=9)$, cardiovascular manifestations $(n=5)$, pulmonary manifestations $(n=3)$, altered consciousness $(n=2)$. Laboratory findings in severe forms were the following: platelets $<100000 / \mu \mathrm{L}(\mathrm{n}=16)$.

Three patients were managed in an intensive care unit because of a multiorgan-dysfunction syndrome. Mechanical ventilation was required in two cases, and cardiac pacing in another case. No extrarenal epuration was required and no death occured.

In all patients, antibiotics were started within 24 hours after admission: amoxicillin $(n=13)$ and doxycyclin $(n=1)$ in non severe forms ; amoxicillin $(n=15)$ and ceftriaxone $(n=7)$ in severe forms. The dosage was $6 \mathrm{~g} /$ day with amoxicillin and $2 \mathrm{~g} /$ day with ceftriaxone. Mean total duration of therapy was 10 days.

CRP and PCT levels at baseline:

Median PCT $(\mathrm{ng} / \mathrm{mL})$ significantly differed $(\mathrm{p}=0.016)$ between severe $(4,5$; range: $0.7-71)$ and non severe forms (0.7 ; range: 0.03-28). Likewise, median CRP significantly differed $(\mathrm{p}=0.04)$ between severe (168.5; range:25-397) and non severe forms (126; range:49-273).

In severe forms, PCT was $\geq 1 \mathrm{ng} / \mathrm{mL}$ in most patients (20/22) patients. In non severe forms, PCT was normal in 4 patients ( 3 of them had been ill for 8 days before their assessment).

CRP and PCT kinetics (figure):

In non severe and severe forms, 18 and 51 samples were collected respectively with a median of 3 samples per patient (range: $1-5$ ).

In severe forms, PCT and CRP peaked within 2 days after admission, and returned to normal values in 7 days

In non severe forms, PCT returned to normal in 4 days, while CRP returned to normal in 7 days. 


\section{DISCUSSION}

All patients fulfilled a clinical diagnosis of leptospirosis, therefore these patients had a leptospirosis of moderate severity, compared to patients from other reports [5]. However, Apache II and Sofa scores significantly differed between severe and non severe cases.

The high CRP and PCT levels observed in most patients of our study are consistent with a SIRS in the setting of leptospirosis.

At baseline, CRP levels are significantly higher in severe forms, but CRP kinetics seems to be similar between severe and non severe forms. PCT, but not CRP, may be normal in non severe forms of leptospirosis, and returns to normal more quickly in non severe forms than in severe forms. Only one observation from the literature described the kinetics of PCT, TNF alpha and IL6 [6], suggesting that PCT alone is a potential marker of leptospirosis severity. PCT has been reported to be a marker of bacteremia [7] as well as sepsis severity [8,9], and our data show that PCT may be a marker of severity in leptospirosis. Furthermore, it has been shown in sepsis that a rapid decrease of PCT translates in a good prognosis. Due to the limited number of patients we assessed, further studies are required to test these hypotheses in the setting of leptospirosis.

Among key leptospire antigens involved in the inflammatory response, lipopolysaccharides (LPS) may trigger cytokines responses involved in disease severity [1]. High TNF alpha levels have related to severity of leptospirosis [10]. TNF alpha is involved in PCT synthesis and PCT may therefore be a marker of disease severity, available in clinical practice. The biological effects of PCT are poorly understood. It has been shown in an animal model of sepsis that PCT can increase mortality, and that its neutralization by an antiserum protects from mortality [11]. The magnitude of SIRS could thus have an impact on infection severity. In turn, therapies likely to control SIRS could be able to reduce lethality of severe sepsis, including severe leptospirosis.

In conclusion, our data suggest that PCT is more discriminatory than CRP in the assessment of leptospirosis severity. PCT levels, alone or as a part of a composite severity score, should be further investigated as a severity marker in leptospirosis. 
1. Ko AI, Goarant C, Picardeau M (2009) Leptospira: the dawn of the molecular genetics era for an emerging zoonotic pathogen. Nat Rev Microbiol 7: 736-747. doi:10.1038/nrmicro2208.

2. Estavoyer JM, Racadot E, Couetdic G, Leroy j, Grosperrin L (1991) Tumor necrosis factor in patients with leptospirosis. Rev Infect Dis 13: 1245-1246.

3. Faine S, Adler B, Bolin C, Perolat P (1999) Leptospira and leptospirosis, $2^{\text {nd }}$ edition, MedSci, Melbourne, Australia.

4. Ko AI, Galvao Reis M, Ribeiro Dourado, CM, Johnson WD Jr, Riley LW (1999) Urban epidemic of severe leptospirosis in Brazil. Salvador Leptospirosis Study Group. Lancet 354 : 820-825. doi: 10.106/S0140-6736(99)80012-9.

5. Panaphut T,.Domrongkitchaiporn S, Thinkamrop B (2002) Prognostic factors of death in leptospirosis: a prospective cohort study in Khon Kaen, Thailand. Int J Infect Dis 6:52-59.

6. Petros S, Leonhardt U, Engelmann L (2000) Serum procalcitonin and proinflammatory cytokines in a patient with acute severe leptospirosis. Scand J Infect Dis 32:104-105.

7. Chirouze C, Schuhmacher H, Rabaud C, Gil H, Khayat N, Estavoyer JM, May T, Hoen B (2002) Low serum procalcitonin level accurately predicts the absence of bacteremia in adult patients with acute fever. Clin Infect Dis 35: 156-161. doi: 10.1086/341023.

8. Meisner M, Tschaikowsky K, Palmaers T, Schmidt J (1999) Comparison of procalcitonin (PCT) and C-reactive protein (CRP) plasma concentrations at different SOFA scores during the course of sepsis and MODS. Crit Care 3:45-50.

9. Castelli GP, Pognani C, Meisner M, Stuani A, Bellomi D, Sgarbi L (2004) Procalcitonin and $\mathrm{C}$-reactive protein during systemic inflammatory response syndrome, sepsis and organ dysfunction. Crit Care 8: R234-342. doi : 10.1186/cc2877.

10. Tajiki H, Salomao R (1996) Association of plasma levels of tumor necrosis factor alpha with severity of disease and mortality among patients with leptospirosis. Clin Infect Dis 23:1177-1178.

11. Nylen ES, Whang KT, Snider RH Jr, Steinwald PM, White JC, Becker KL (1998) Mortality is increased by procalcitonin and decreased by an antiserum reactive to procalcitonin in experimental sepsis Crit Care Med 26:1001-1006. 
Figure . Kinetics of procalcitonin (upper curves) and C-reactive protein (lower curves) in severe and non severe forms of leptospirosis.
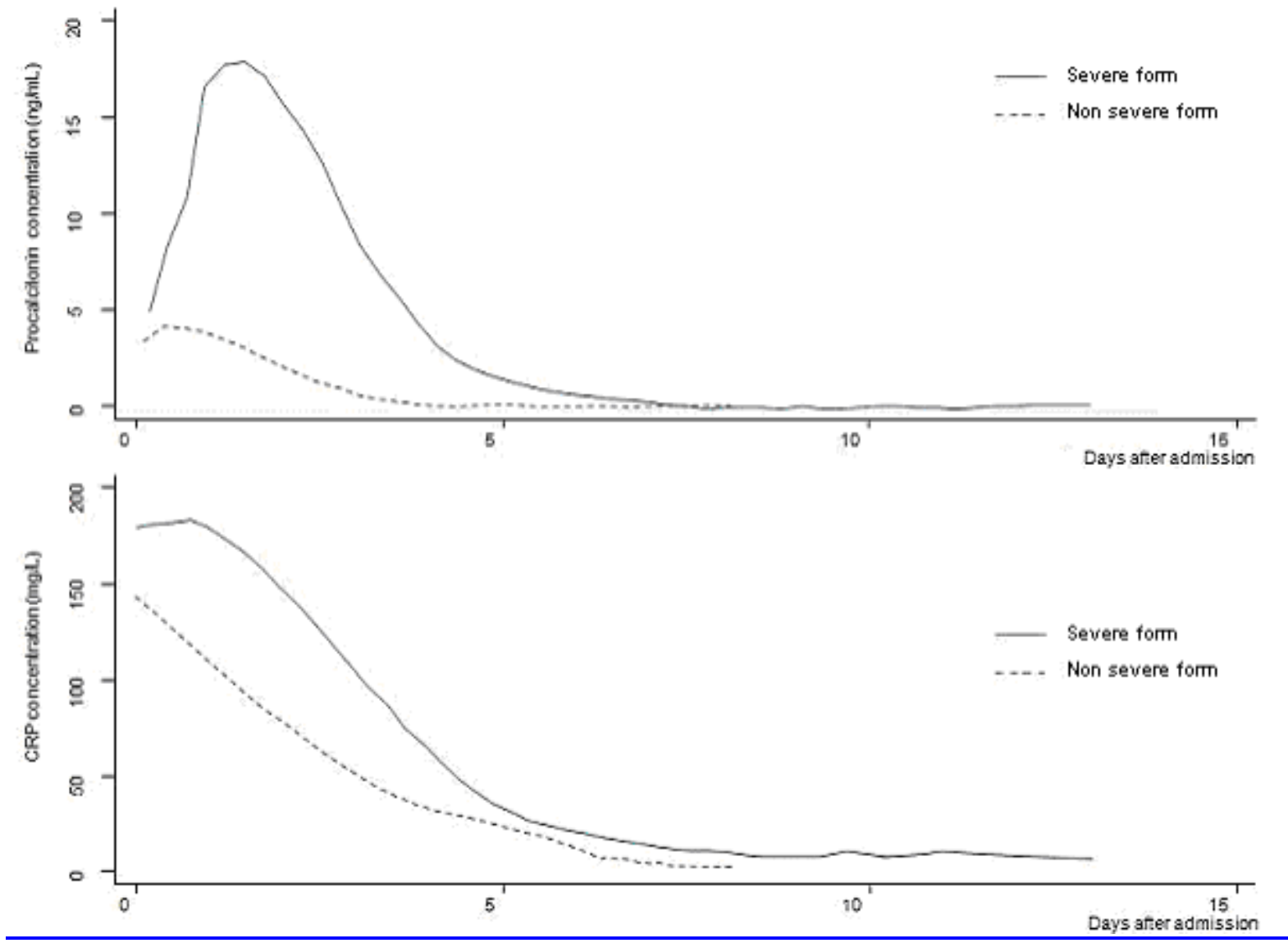
Table 1: Baseline characteristics in patients with non severe and severe leptospirosis

\begin{tabular}{|c|c|c|c|c|}
\hline Parameters & $\frac{\text { Study population }}{(\mathrm{n}=36)}$ & $\frac{\text { Non severe form }}{(\mathrm{n}=14)}$ & $\frac{\text { Severe form }}{(\mathrm{n}=22)}$ & $\underline{P \text { value }}$ \\
\hline Male sex $\mid \mathrm{n}(\%)$ & $\underline{33(91.7)}$ & $\underline{12(85.7)}$ & $\underline{21(95.5)}$ & $\underline{0.30}$ \\
\hline Age (yeats)* & $\underline{40.0(10.0-71.0)}$ & $\underline{31.0(17.0-71.0)}$ & $\underline{45.0(10.0-63.0)}$ & $\underline{0.05}$ \\
\hline Modified|APACHE II score* & $\underline{7.0(0-21.0)}$ & $\underline{4.0(0-13.0)}$ & $\underline{10.0(3.0-21.0)}$ & $\underline{0.001}$ \\
\hline Modified|SOFA score* & $\underline{5.0(0-12.0)}$ & $\underline{2.0(0-5.0)}$ & $\underline{5.0(3.0-12.0)}$ & $\underline{0.001}$ \\
\hline Serum craatinine $(\mu \mathrm{mol} / \mathrm{l}) *$ & $115.5(67.0-568.0)$ & $\underline{105.5(75.0-150.0)}$ & $\underline{142.5(67.0-568.0)}$ & $\underline{0.05}$ \\
\hline Platelets kount $\left(/ 10^{9} / \mathrm{L}\right)^{*}$ & $\underline{112.5(17.0-332.0)}$ & $\underline{136.0(101.0-302.0)}$ & $\underline{93.0(17.0-332.0)}$ & $\underline{0.02}$ \\
\hline$\underline{\mathrm{CRP}}$ at entry $(\mathrm{mg} / \mathrm{L}) *$ & $\underline{145.5(25.0-397.0)}$ & $\underline{126.0(49.0-273.0)}$ & $\underline{168.5(25.0-397.0)}$ & $\underline{0.04}$ \\
\hline Procalcitфnin at entry $(\mathrm{ng} / \mathrm{mL})^{*}$ & $\underline{1.5(0.03-71.0)}$ & $0.7(0.03-28.0)$ & $4.5(0.7-71.0)$ & $\underline{0.016}$ \\
\hline Days of symptoms to admission* & $\underline{4.0(3.0-5.0)}$ & $\underline{3.0(0-8.0)}$ & $\underline{4.0(1.0-8.0)}$ & $\underline{0.06}$ \\
\hline Duration of hospitalization (days)* & $4.5(2.0-15.0)$ & $\underline{4.0(2.0-8.0)}$ & $5.5(2.0-15.0)$ & $\underline{0.09}$ \\
\hline
\end{tabular}

* mediah (range) 